\title{
HOW TO SCREW THINGS WITH WORDS
}

\section{Introduction}

In general, and increasingly in recent years, scholars have laboured to place the facts of abuse uncovered and analysis of dynamics developed on its own ground into one academic straightjacket after another, attempting to prise apart and recategorize and cabin and control and ratiocinate their meanings and implications, abstracting the work into tiny fractionated bits to be confined and domesticated and thus, seemingly, made newly credible and acceptable, even important. The process could be a subject of study in itself. Why are ideas seen as valuable, exciting, worth thinking about, only if cast backwards into already familiar words and pre-existing frameworks, only when reconfigured within the principles of some big man's prior thought?

- $\quad$ Catharine A. MacKinnon ${ }^{1}$

Once upon a time there was an argument over pornography. Liberals held that expression should not be restricted unless it could be shown to be in clear violation of Mill's 'harm principle'. Some feminists took the view that pornography did harm, degrade and brutalise women. Liberals replied that the issue was complicated, and that they had not seen enough evidence to justify taking such a drastic step as censorship. Freedom of speech was paramount. The debate seemed to have reached an impasse. And then, suddenly, a new argument was discovered, which had the potential to meet liberals on their own most sacred ground. This argument - which has come to be known as the 'silencing argument' - held that one of the harms of pornography is that it silences women. In that case, there might be a case for censoring pornography precisely because freedom of speech is so important. But does it work? The jury - it seems to be agreed on both sides - is still out. ${ }^{2}$

At least, that is how the story is often told. In fact, the silencing argument did not appear so suddenly. The idea that pornography robbed women of a voice had always been a part of the radical feminist critiques of porn which began to appear in the late 70's and 80's - most notably by Andrea Dworkin and Catharine A. MacKinnon $^{3}$ - at a moment when pornography had unmistakably ceased to be a

\footnotetext{
${ }^{1}$ MacKinnon (2012; p.vii).

2 For example, Langton (2009) only claims that the argument is 'coherent' and 'plausible', not that it is ultimately sound.

${ }^{3}$ See e.g. Dworkin (1979), MacKinnon (1987), Dworkin \& MacKinnon (1998).
} 
niche or specialist good, and was instead becoming one of world's biggest industries and a staple of mainstream culture. ${ }^{4}$ MacKinnon's version of the argument was then translated into terms more readily digested by analytic philosophers by Rae Langton in a 1993 article, 'Speech Acts and Unspeakable Acts', ${ }^{5}$ sparking a lively debate and research programme which has been running ever since. ${ }^{6}$ But twenty years have now gone by since the publication of Langton's article. The silencing argument can no longer be described as new.

My intention in this paper is not to join in the existing debate on the silencing argument, but to call time on it. In its current form, it is going nowhere - and has been en route for too long already. Yet the argument, I believe, contains an indispensable insight, and more radical potential than is usually acknowledged either by its defenders or by its opponents.

The paper has the following structure. In the first section, I set out Langton's rendering of the silencing argument, which draws heavily on the work of the philosopher of language J. L. Austin. In the second section, I critically examine the debate that follows in its wake. In the third section, I argue that we might better preserve the insight and unleash the radical potential contained in the silencing argument by shaking off the dead hand of Austin and effecting a return to MacKinnon. Finally, I suggest that we must take a wider view of the silencing argument if we are to realise its full significance and critical force.

The crucial insight shared by Austin, MacKinnon and her interpreters is that speech does things, and moreover, that the speech of one person may affect what another is able to do with her speech - through shaping the way in which she is viewed, the identities that are constructed for her, and as a consequence, the way in which she is understood when she speaks. There can be no sharp disconnect between i) what is said about us, ii) who we are, and iii) what we are able to say. This very simple point is already enough to show what is wrong with the tendency to equate freedom of speech with the absence of censorship. Freedom of speech is a matter of having some control over our own voices, which means having a say in who we are and how we are seen, and not having these things fixed for us by those in positions of

\footnotetext{
${ }^{4}$ Since then, the porn industry has continued to flourish and evolve, and in 2003 is estimated to have grossed $\$ 34 \mathrm{bn}$ globally (and more than $\$ 8 \mathrm{bn}$ in the U.S. alone).

${ }^{5}$ Reprinted in Langton (2009).

6 Proponents of versions of the argument include: MacKinnon (1987; 1994); Maitra (2009); McGowan (2009); West (2003; 2012).
} 
superior power. Contrary to appearances, then, the silencing argument is not just or even primarily - an argument about censorship or other legal measures. ${ }^{7}$ It is not just about porn. And it's not even 'just' about women. It's about the relationship between speech, identity, and freedom. It would be hard to think of anything more central to politics.

\section{The 'silencing argument' against pornography}

In a reaction against the liberal debate over the alleged harms caused by pornography, Catharine MacKinnon argues that pornography does not just cause harm: it is harm. Rather than regarding pornography primarily as an act of speech or expression (which may then go on to have various effects), we should recognise pornography for what it is: the very act of subordination. ${ }^{8}$ More particularly, pornography subordinates women partly by silencing them: 'The free speech of men silences the free speech of women. ${ }^{\prime 9}$

Many philosophers have struggled to make sense of this. As MacKinnon herself observes: 'to say that pornography is an act against women is seen as metaphorical or magical, rhetorical or unreal, a literary hyperbole or propaganda device.'10 One commentator notes that whilst philosophers may appreciate the idea that pornography depicts or perpetuates subordination, they cannot see how it could literally constitute subordination. ${ }^{11}$ MacKinnon's claim is duly dismissed as a particularly strident expression of a claim accepted even by prominent opponents of restrictions on pornography: depictions of subordination tend to perpetuate subordination. ${ }^{12}$ We remain firmly stuck in tedious empirical disputes over cause and effect, and it seems that MacKinnon has added nothing of interest.

\footnotetext{
${ }^{7}$ It's important to realise that MacKinnon deliberately focuses on civil legal remedies rather than on 'censorship' in the usual sense. The stated aim of her and Andrea Dworkin's Minneapolis Ordinance was to empower victims of pornography to take legal action against the producers of material that had contributed to crimes committed against them.

${ }^{8}$ MacKinnon (1987; p.176).

${ }^{9}$ Catharine MacKinnon (1987; p.156).

${ }^{10}$ MacKinnon (1994; p.8).

11 Saul (2006; p.229).

${ }^{12}$ In ruling Dworkin and MacKinnon's 'Indianapolis Ordinance' unconstitutional, Judge Easterbrook agreed: 'We accept the premises of this legislation. Depictions of subordination tend to perpetuate subordination. The subordinate status of women in turn leads to affront and lower pay at work, insult
} 
Enter Rae Langton. Langton's project is to show, in terms acceptable to analytic philosophers, that MacKinnon is making a distinctive claim after all - not just adding a rhetorical flourish - and, moreover, that the claim is both coherent and plausible. Langton does this by developing a connection which MacKinnon also makes - albeit only in passing ${ }^{13}$ - between the phenomenon of silencing and the work of J. L. Austin on 'speech acts', as set out in his 1961 book How to Do Things With Words. Austin makes a threefold distinction between 'locutionary', 'illocutionary' and 'perlocutionary' speech acts: a locutionary act is the act of speaking certain words (e.g. "I do"); an illocutionary act is an act performed in speaking those words (e.g. the act of marrying); and a perlocutionary act is something which happens as a consequence of speaking certain words and thereby performing an illocutionary act such as marrying (e.g. irritating the bride's family).${ }^{14}$

Langton suggests, with MacKinnon, that we interpret the silencing claim as the claim that pornography performs a certain illocutionary act. Pornography does not just depict things, and does not merely say something about women: it does something to them. Just as the speech act of saying (or writing) the words 'Blacks are not permitted to vote' can discriminate against black people, so pornography can be seen as an act of relegating women to an inferior, subordinated status as sex objects. In particular, it is claimed that pornography constitutes an illocutionary act of silencing women, and that it does so through the projection of a certain image of what women are and how they behave. As MacKinnon and others have observed, much pornography propagates a 'rape myth': the idea that all women, at all times, whether they admit it or not, 'really' want sex, and that their refusals of sex are not sincere or authentic; women say "no" but mean "yes". If this myth is accepted and internalised, this can result in a situation where women suffer 'illocutionary disablement': they are free to speak words of refusal - e.g. to perform the locutionary act of saying "no" - but are debarred from performing the illocutionary act of refusing. The silencing performed by pornography is 'illocutionary' in a double sense: it is an illocutionary act of silencing; and it silences women at the illocutionary level, by preventing them from doing things with their words.

and injury at home, battery and rape on the streets...but...this simply demonstrates the power of pornography as speech.' (771 F.2nd 329 (7th Cir. 1985)).

${ }^{13}$ MacKinnon (1994; fn.31, pp.86-7).

${ }^{14}$ The distinction between 'illocutionary' and 'perlocutionary' is not unproblematic, as we'll see later, but this must be temporarily set aside in order to describe the contemporary formulation of the silencing argument and the debate that ensues. 
Langton makes further use of Austin in order to explain exactly how this is possible. Austin is interested not just in how we do things with words, but also in how we can fail to do things. Successful performance of illocutionary acts depends on the fulfilment of what Austin terms 'felicity conditions'. For instance, the words 'I do' can only function as an illocutionary act of marrying if they are said in the presence of a priest (or equivalent), and if neither the bride nor the groom is already married. And according to Austin - although this is disputed - certain illocutionary acts, such as warning, have as one of their felicity conditions the 'uptake' of the words and their intended meaning by the hearer. If I say, "There is a bull in that field", I only succeed in warning you if you understand what I say, and its intended force as a warning.

Langton transfers this to the case of refusal. MacKinnon's claim is that pornography projects an image of women that prevents their refusals from counting as refusal. Langton translates this into the claim that pornography's perpetuation of the rape myth removes a 'felicity condition' of successful refusal. A woman can speak the words that would otherwise constitute the act of refusing sex, but if the man has internalised the rape myth, he may not interpret her as refusing at all: she may fail to secure the 'uptake' required in order to perform the act of refusal. If this is what pornography does to women, argues Langton, then it silences them. The value of freedom of speech can therefore be turned against the liberal opponent of censorship: the restriction of the pornographer's freedom of speech is arguably justified by the greater good of protecting the freedom of speech of women. At least, the question is no longer about the correct balance between freedom of speech and some other good such as equality - a balance which usually swings in favour of freedom of speech. Rather, it's a question of balancing freedom of speech against freedom of speech. 'Freedom of speech' can no longer be played as a trump card against the feminist critic of pornography. The question becomes: whose freedom?

The silencing argument as laid out here is commonly perceived - by its proponents and opponents alike - as having important advantages over the standard, harmbased arguments against pornography: first, it is seen as offering to bypass empirical questions of cause and effect (porn just is the harm of subordination and silencing); second, its exclusive focus on the value of freedom of speech is thought to carry with it both a certain elegance and also the possibility of an 'internal critique' of the liberal opponent of censorship which exposes her position as self-contradictory ("if you 
really think freedom of speech is the most important thing of all, then you have a reason to restrict pornography"). Nevertheless, the argument remains highly controversial. In the next section, I examine some of the reasons why.

\section{Red herrings and dead white men}

After an initial murmur of appreciation, the silencing argument is typically met with a barrage of objections. It's helpful to sort these into two main categories. The first strategy is to accept, if only for the sake of argument, the essentials of Langton's story about what pornography does to women, but to deny that this constitutes 'silencing' - or at least, that it's the sort of silencing that threatens freedom of speech. The second strategy is to deny Langton's story outright: rather than "That's not silencing!", this response says "That's just not what happens!". I'll look at each of these strategies in turn.

\section{i) “That's not silencing!"}

The first strategy usually takes one of three paths. The best-known traveller of the first is Ronald Dworkin (in an early direct response to MacKinnon). ${ }^{15}$ Making use of Isaiah Berlin's famous distinction, Dworkin argues that if pornography only prevents women from being able to do certain things with their words (like refuse sex) - as opposed to preventing them from uttering those words at all - then it restricts their 'positive' freedom (a freedom to do something); but if the state intervenes to censor pornography, this removes a 'negative' freedom (a freedom from artificially-imposed constraints). ${ }^{16}$ Since, for Dworkin and many others, negative freedoms 'trump' positive ones, the freedom of the pornographer to produce and distribute pornography must be upheld.

There is no shortage of possible replies to this one. We might doubt that the distinction between 'positive' and 'negative' liberty can be as clearly drawn as Dworkin needs it to be. ${ }^{17}$ Even accepting the distinction, we might reject the premise that negative liberty should always take priority over positive liberty - the legal

\footnotetext{
15 Dworkin (1993).

${ }^{16}$ Berlin (1970).

${ }^{17}$ See McCullum (1967) for an influential criticism of the 'positive' / 'negative' framework.
} 
enforcement of speed limits is a restriction of negative liberty, and most people think that this is justified by the protection of our positive freedom to travel in safety and comfort. But in any case, Langton's claim is that pornography compromises women's negative freedom: it's not just that women are unable to make themselves understood - as might be the situation of someone with a severe speech impediment. The claim is that they are prevented (by pornography) from making themselves understood. ${ }^{18}$ To borrow an analogy used by Caroline West, it is as if the Government were to install a chip in the brains of citizens, enabling it to switch off those citizens' ability to understand English whenever a member of a particular group speaks. This, it seems clear, would be to restrict the freedom of speech of members of that group, by actively preventing their comprehension by others. ${ }^{19}$

Whichever of these replies we favour, one thing is clear, and that is that there are two separate distinctions here which must not be run together. On the one hand, there is a distinction between merely unable, and being actively disabled by some external agency. This, such as it is, is the distinction relevant to the contrast between 'positive' and 'negative' liberty. Then there is the different distinction between ways of conceptualising speech: e.g. as the uttering of words (Ronald Dworkin's understanding), or as the performance of successful communicative (and other) acts (Langton's understanding). These distinctions really do not have much to do with one another, and so if we think of freedom of speech as a matter of the freedom to perform certain 'illocutionary' rather than 'locutionary' acts, this leaves it an open question - at least on the face of it - whether we are concerned here with a 'negative' or a 'positive' freedom. ${ }^{20}$

\footnotetext{
${ }^{18}$ Langton $(1999 ; 2009)$. We might also take issue with Dworkin's choice of analogy. Dworkin (1993; pp.38, 40) compares the situation of a woman attempting to refuse unwanted sex with that of a 'flatearther' who cannot find an audience that will take his views seriously. Aside from its offensiveness, the analogy is also badly designed, since - as Langton (1999; p.129) points out - Dworkin does not suggest that the flat-earther's words fail to secure uptake (i.e. minimally correct comprehension) in their hearers. ${ }_{19}$ West (2003).

${ }^{20}$ Green (1998) also confuses the two distinctions. Green distinguishes between silencing in a 'broad' and 'narrow' sense: we are silenced in a broad sense, he concedes, if rendered unable to perform certain illocutions, whereas we are silenced in the narrow sense only if we are gagged or otherwise prevented from performing locutions - and we are not justified in silencing in the narrow sense in order to prevent silencing in the broad sense. He connects this with an interpretation of the silencing argument as holding that one is silenced 'whenever one's words fail to be taken with the force one intends' (p.302), which is an independent claim, and in any case obviously incorrect as an interpretation of Langton. Similarly, he reads Hornsby as equating silencing with 'failure to provide conditions of reciprocity'. What she actually says is: 'Silencing is the process of depriving of illocutionary potential' (2011; emphasis added).
} 
Rather than dwell on this objection any further, I'll now briefly mention two further versions of the first strategy. Like Dworkin's, both of these objections make use of a famous distinction by a dead white man. This time, however, the dead white man is not Berlin, but Austin himself - although the distinction, I'll suggest later, is just as dubious. Seeking to turn the Austinian machinery back against Langton, proponents of these two objections target one or other aspect of the double sense identified in Section I - in which pornography's silencing of women is held to be 'illocutionary'. The first version denies that pornographic expression is an illocutionary act of subordination or silencing: at most, it has these as 'perlocutionary effects' ${ }^{21}$ We must therefore examine the evidence; and the evidence, many believe, is inconclusive. Proponents of the second version of this strategy hold - with apparently straight faces - that what women allegedly suffer from as a result of porn is not 'illocutionary disablement', but merely a case of 'perlocutionary frustration':22 they perform acts such as refusal, all right; they just can't rely on their refusals being respected. ${ }^{23}$

If these distinctions don't seem very satisfying, they shouldn't. What difference does it make whether we say that women are silenced, or 'caused to be silenced'? Does it really matter whether women are 'illocutionarily disabled' or 'perlocutionarily frustrated'? Do these states feel any different from the inside? I'll return to these matters in the next section, but it's worth making one point now. This is that the distinction between 'illocutionary' and 'perlocutionary' has as little to do with the contrast between 'negative' and 'positive' freedom as the distinction between 'illocutionary' and 'locutionary' did. Although proponents of the two sub-strategies

\footnotetext{
${ }^{21}$ Saul (2006) is one example of someone who denies that pornography is an illocutionary act of subordination or silencing, although in many respects she is sympathetic to Langton et al.

${ }^{22}$ Jacobson (1995; p.72). Jacobson argues that women can refuse, because even if their utterance of words like 'no' fails to count as refusal, they can still do other things, like wriggle (note: not a joke). ${ }^{23}$ Jacobson further claims that, by claiming that the raped woman doesn't really refuse, Langton debars herself from describing the rape myth scenario as one of rape. Langton's withering reply is that Jacobson has failed to grasp the distinction between not refusing and consenting (see her response to Jacobson in Langton (2009)). Though true, this not the most effective line for Langton to take: Jacobson might re-word his objection, accusing Langton of being committed to a view whereby women positively consent when they say "no" (still rendering her unable to recognise rape as rape). Langton also seems to concede too much by granting that the woman does not refuse. An adequate reply, I think, would have to allow both a (distorted) sense in which the woman doesn't refuse perhaps even consents - and a clear sense in which she does refuse, whilst also acknowledging that the understanding of 'rape' and 'consent' that is appropriate for the purposes of feminist political philosophers may not be the same as the understanding that is appropriate for legal purposes. I come back to this in Section III.
} 
just mentioned often run together their appeals to the 'illocutionary' / 'perlocutionary' distinction with the Ronaldian ${ }^{24}$ argument that freedom of speech isn't a matter of being able to do whatever you want with your words - thrill an audience, convince them that the world is flat, etc. - that move is as clearly invalid as it was in the previous case. To revisit West's analogy: the Government installs the brainchips; every time I try ${ }^{25}$ to say something, my audience's ability to understand me is switched off. It seems natural - to the extent that applying the 'negative' / 'positive' distinction is ever natural - to say that my negative freedom is infringed. Does this change, depending on whether we think of the event of my being understood as a 'perlocutionary' effect, rather than as a condition of my performance of an illocutionary act? No. Suppose we change the example, to make it more Cassandra-like: I am understood, but the Government flicks a switch which prevents anyone from believing me. Or: the Government erases people's memories five minutes later, so that I never achieve my objectives in speaking to others. Does that mean that we can no longer say that my negative liberty is infringed, in the standard sense, i.e. that I am prevented by another agent from doing things? I see no reason why it should. Although 'frustrated' would be a pretty good description of my state in this scenario, we shouldn't forget that this is a word with not only an adjectival form but also a transitive verbal one: ' $x$ frustrates $y$ '; 'the Government frustrates $m e^{\prime}$.

\section{ii) “That's just not what happens!"}

I turn now to the second main strategy mentioned earlier: the line which denies that Langton's account of what pornography does to women's speech corresponds to reality. This objection is rarely developed very far in the literature, but it seems to be in the background - and used as back-up - in almost all discussions of the silencing argument.

As we have seen, Langton's influential presentation of the silencing argument gives a central place to a rather abstract, deliberately simplified rape-scenario: a woman says 'no' to a man who is making sexual advances on her; she fails to secure the 'uptake' which is required - on Langton's extrapolation from Austin's philosophy of language - in order for her utterance to constitute the illocutionary act of refusal - i.e.

\footnotetext{
${ }^{24}$ To distinguish this Dworkin from Andrea, of course.

${ }^{25}$ In the case I'm imagining, I do actually speak, in the sense of uttering words. But note how natural it is to describe this situation with the phrase I just found myself writing: 'whenever I try to say anything'. This seems to me to lend intuitive support to Langton's policy of regarding uptake - or at least the possibility of uptake - as a felicity condition of certain kinds of speech.
} 
because the man does not understand her 'no' as a refusal (having been exposed to the 'rape myth' via the powerful medium of pornography), she doesn't (and cannot) really refuse; hence, she is silenced (qua illocutionarily disabled). She is also raped.

One thing that should be immediately clear about this is that it does not work well as a straightforward description of rape, for any number of reasons: in real life, many other words than 'no' may be uttered; sometimes 'no' will not be uttered; sometimes there will be physical resistance (although sometimes not); and the rapist's attitude towards and interpretation of the woman and her behaviour is likely to be complex, partially ambiguous or even indeterminate, and imperfectly represented at the level of conscious thought or belief. The scenario envisaged is instead a model or device, employed to make a point - a point about the way in which social context, itself a partial product of speech acts, can make a difference to the sorts of speech acts that are and are not possible for us. Whether the model is a helpful or appropriate one is arguable. ${ }^{26}$ But a model is certainly what it is.

That, however, is not always how it is treated. Leslie Green, for example, notes that this is 'almost certainly the least likely form of date rape' - with the distinct air of someone who thinks he is saying something relevant. ${ }^{27}$ Daniel Jacobson, meanwhile, obligingly goes through the motions of supposing 'that exposure to pornography has, as Langton imagines, brought some man sincerely to think that a woman's saying "no" to sex is just another way of consenting', in order to consider how we should judge such a case, but 'confesses' to finding it 'unlikely'. ${ }^{28}$ The gentle, headmasterly condescension of Green and Jacobson is almost ulcer-inducing, and Langton herself is sometimes guilty of encouraging their mistake. She concedes that

\footnotetext{
${ }^{26} \mathrm{My}$ view is that it could be helpful to clarify a philosophical point in passing, but that when fixated upon, it may do more harm than good: i) by distracting us from questions of the reality of rape and of the actual effects of porn (as opposed to questions of what porn might do); and ii) by confining our attention to the cognitive aspects of the attitudes which porn may engender in people, and men in particular (how they understand or interpret women's utterances), rather than on the affective or erotic aspects of these alleged effects. Langton has more recently aimed to remedy this (see 'Beyond Belief' in Langton (2009)), although simply revisiting MacKinnon's Only Words would also suffice:

MacKinnon continually emphasises that this is an issue of how women are seen and not seen, desired and detested, and focuses on the (presumably non-cognitive) 'eroticization' of hierarchy and violence which she traces to pornography.

${ }^{27}$ Green (1998; p.298). Green concedes that this is an 'important case' nonetheless, but only for the relatively peripheral legal question of what we should say in cases of non-consensual or forced sex where mens rea is absent (as occasionally happens with sleepwalkers, for example). I think it's fair to say that this is not the sort of 'importance' Langton is aiming for.

${ }^{28}$ Jacobson (1995; p.77).
} 
she 'does not know' how common the scenario described actually is, ${ }^{29}$ in a way which seems to affirm that this is the empirical question on which our attitude to porn and its regulation should hinge: her project as a philosopher is to establish the conditional, 'If scenario $S$ obtains, then that counts as silencing', and the contribution of empirical social science must be to establish whether or not the antecedent is satisfied (if it is, then 'it may be wrong for a government to allow pornographers to $\left.\operatorname{speak}^{\prime}\right) \cdot{ }^{30}$

The problem with this is that it does indeed seem extremely implausible to suggest that a common way in which rapes happen is by the rapist simply, sincerely and consciously believing that the woman (equally simply, sincerely and consciously) means 'yes' when she says 'no'. Rape is not some kind of hilarious sit-com-style case of crossed wires. The closest that can be found to a documented real-life instance of rape-by-misunderstanding - a case which is duly seized on by those attracted to the silencing argument - is the 1975 case of DPP $v$. Morgan, where a husband invited his friends home with him to have sex with his 'kinky' wife, who, he promised them, would put on an entirely insincere show of resistance. ${ }^{31}$ Even in this case, however, the jury's verdict was that the men had in fact been aware that Mrs Morgan's refusal was genuine.

The literal-minded interpretation of Langton's scenario is surely uncharitable, rendering her point implausible to the point of offensiveness: rape does not happen through simple misunderstanding. It may be perfectly legitimate, however, to use an artificially simplified example to make a general point about how speech can (and does) affect the way in which people are and can be understood, which means affecting the speech acts they are able to perform, which means - it's not crazy to suggest - affecting their freedom of speech. In this sense, Langton's device should be understood primarily as a pedagogical one, and to worry that it might not accurately reflect the reality of rape is like worrying that the plastic models used to teach medical students how the human body works are defective because the human body is not made of plastic. And if we want to know what, more exactly, this

\footnotetext{
${ }^{29}$ Langton (2009; p.58).

30 ibid, p.63.

${ }^{31}$ This case established the precedent of mens rea for rape, such that a man is innocent of rape so long as he sincerely believes the woman to have consented. In DPP $v$. Morgan, the defendants were found guilty only because the judge deemed them, despite their claims to the contrary, not to have had this belief. This criterion remained in place until the 2003 Sexual Offences Act, which extends the definition of 'rape' to cover those cases where the perpetrator does not 'reasonably believe' that the other person consents (my emphasis).
} 
pedagogical device can teach us, I think the answer is that it can illuminate something about how the politics of sex and agency under patriarchy work. That something may be too complex to be reduced to a simple formula, or to be neatly proved or disproved; but the lesson is not that men simply misunderstand women when they say "no", because they've watched porn and so they think that women say "no" to sex when they mean "yes". It is something more like: the particular system of unequal power between men and women, to which porn contributes (or of which it forms a part), is one in which women's agency and worth is denied in such a way that their protest or refusal - not just to sex or to sexual advance, but especially to these - is effectively defused or nullified in ways that are not always easy to detect, let alone to articulate or to combat, but which have to do with the social status and identity that are accorded to women and, relatedly, with the way in which their attempts at protest and refusal are interpreted. And that, I would suggest, is what happens - happens so much that all but the most disruptive, traumatic or inconvenient instances of it are virtually invisible.

This is one point at which reflection on the parallels with Austin's work could act as a useful corrective. When Austin considers a scenario in which the vicar conducting a marriage ceremony turns out to be a monkey in disguise - so that the unfortunate couple's words 'misfire' and they fail to marry - nobody gently explains to Austin that, whilst this would be deeply unsettling were it to come to pass, this sort of thing rarely, if ever, actually happens. It is taken for what it is: a device which is meant to illustrate something about the practical functioning of speech and language. Not how it might function, but how it does.

\section{MacKinnon unmodified}

'...the work we did has provided, among other things, fodder for caricature and pornography and libel, ideas to be appropriated without reference or attributed to others, concepts to be twisted or made superficial as their clear original articulation is elided, intellectual background to be taken for granted, and grist for numerous academic mills, as various schools of thought contend to dismiss it from or subordinate it to pre-existing methodologies. Sometimes the attempts have been tortured, sometimes illuminating, if frankly modestly so. Frequently our work is treated as a trampoline on which others perform showy tricks or 
described as a distant land seen from an overflying jet or a war zone visited by tourists...' 32

In the last section, I sketched the shape of the debate over the silencing argument, and also tried to give a sense that there is something unsatisfactory about it. From the passage quoted above, it seems clear that the dissatisfaction is one which MacKinnon herself shares - although it's striking that this is rarely, if ever, acknowledged even by those who take themselves to be her defenders and allies.

What I want to do in this last main section is to try to get a clearer overview of what it is that has gone wrong, and of what a better shape might be for the debate to take. To a very large extent, I'll argue, this can be done simply by reminding ourselves of what MacKinnon herself has known and said all along.

As we saw in Section II.i), a common strategy against the silencing argument focuses on the Austinian distinction between 'illocutionary' and 'perlocutionary'. What one side calls 'illocutionary' the other calls 'perlocutionary'. ${ }^{33}$ But all seemed to be satisfied that this is a dispute which is both meaningful and important. Against this, I expressed a suspicion that the distinction is both collapse-prone and beside the point. And MacKinnon seems to agree, noting with characteristic brusqueness: 'Although [Judith] Butler does not seem to understand it, both illocution and perlocution are causal theories, the former more immediately and with fewer intervening contingencies than the latter. ${ }^{34}$ In other words, these are two alternative ways of describing cases where we bring about some change or other in the world, with one term tending to be used to describe cases where the effect is more immediate, direct or inevitable - but neither description would be strictly incorrect.

MacKinnon's impatience with the fetishization of the 'illocution' / 'perlocution' distinction reflects her more general impatience with the tendency to fetishize Austin, whom she clearly views with respect rather than reliance: 'Austin is less an authority for my particular development of "doing things with words" and more a foundational exploration of the view in language theory that some speech can be

\footnotetext{
${ }^{32}$ MacKinnon (2012; p.vii).

${ }^{33}$ This has also been couched - misleadingly, as we'll see - as a dispute between 'causal' and 'constitutive' theories - with MacKinnon as arch-'constitutivist' (Maitra \& McGowan (2012)).

${ }^{34}$ MacKinnon (2012; p.xi).
} 
action.' ${ }^{35}$ Elsewhere, she objects to the tendency for commentators to view her and Andrea Dworkin's work on pornography through the lens of Austin's work on speech acts, 'as if our work, now unnamed, is really, although we did not know it, a subprovince of Austin to be confined and tilled as such, also implying we cannot be doing something he did not do.' ${ }^{36}$

Of course, one reaction to this might be to say that MacKinnon is cutting off her nose to spite her face. If we dispense with the Austinian apparatus exploited by Langton, are we not back in the same situation which Langton aimed to remedy? That is to say, we are back with a set of claims which sound hyperbolic and obscure: that porn 'is' subordination; and that it 'silences' women (when we know very well that women can open their mouths and talk just like anybody else). For MacKinnon, however, the appearance of mystery is merely a function of the sort of approach she rejects. ${ }^{37}$ That appearance can be dispelled fairly easily without the aid of heavy Austinian machinery. We don't have to set the whole of that machinery in motion in order to hold onto the insight that speech does things - and that one of things it can do is affect (for better or for worse) the sorts of things people are able to do with their speech. That much seems clear. And what MacKinnon thinks porn does is subordinate and silence women. The claim may be found plausible or not, but it's only baffling if we make the mistake of assuming that this is being presented as a strictly non-causal claim (recall MacKinnon's explicit acknowledgement that 'both illocution and perlocution are causal theories'). ${ }^{38}$

Does this mean that MacKinnon's claim is empty rhetoric, after all, adding nothing to existing causal claims about harm? Not really, because what is to be rejected is the reification of distinctions, not distinctions per se. The distinction between 'illocutionary' and 'perlocutionary' may only be a distinction between two modes of description - "She broke the glass", versus "She caused the glass to break" - but in any given context, some modes of description will be more appropriate than others. In the light of MacKinnon's own explanation of the relationship between 'illocutionary' and 'perlocutionary', it seems clear enough that by identifying porn with subordination (rather than following the more usual practice of identifying it as a cause), MacKinnon is making a claim about the intimacy, immediacy, and

\footnotetext{
${ }^{35}$ MacKinnon (1994; fn.31, pp.86-7).

${ }^{36}$ MacKinnon (2012; p.viii, fn.4).

37 ibid, p.vii.

38 ibid, p.xi. Emphasis added.
} 
systematicity of the relationship she sees between pornography, on the one hand, and violence and discrimination against women, on the other. That is not empty, and nor is it mysterious. In fact, MacKinnon emphasises how mundane her claim is, drawing constant comparisons with cases where we would be inclined to find a 'perlocutionary' description of a speech act highly perverse: it would be odd to insist that the putting up of a "Whites Only" signed was not an act of discrimination, but merely 'caused' discrimination to occur further down the line. But that, thinks MacKinnon, just shows that we have understood something about racial hate speech that we have not yet understood about pornography.

To claim that pornography subordinates and also silences women is to suggest that views of what women are - what they are for and what they are worth - can become so profoundly distorted that there is a sense in which women become what they are seen to be, and say only what they are heard as saying. This is what gives us the sense in which the woman who says "no" to sex does not count as refusing at all - in this sense she is silenced. But there is also, of course, a clear enough sense in which she does refuse - in this sense, she is raped (or 'perlocutionarily frustrated', as some prefer to put it). Evidently enough, some ways of putting things are better than others.

Analytic philosophers, notoriously, often have great difficulty with claims of the form, ' $p$ and not- $p$ ', even where the contradiction can easily be shown to be of a superficial and benign kind (logically, if not politically). MacKinnon has no such trouble. This comes out especially clearly in her approach to the question of whether porn is or is not speech - another hotly contested issue in the debate over silencing. ${ }^{39}$ On the one hand, she refers to the 'lie' that pornography is speech, ${ }^{40}$ and remarks: 'To take the claim seriously enough even to rebut it that this practice of sexual violation and inequality, this medium of slave traffic, is an opinion or a discussion is to collaborate, to some degree, in the legal and intellectual fraudulence of its position.' ${ }^{41}$ And on the other hand, a little later: 'I am not saying that pornography is conduct and therefore not speech, or that it does things and therefore says nothing and is without meaning, or that all its harms are noncontent harms. In society, nothing is without meaning. Nothing has no content...' ${ }^{42}$ Demonstrating beyond

\footnotetext{
39 See e.g. Hornsby (2011), Antony (2011).

${ }^{40}$ MacKinnon (1994; p.xi).

${ }^{41}$ ibid, p.x.

${ }^{42}$ ibid, p. 20 .
} 
doubt that this is not the result of a simple amnesia but is instead a self-conscious and deliberate stance, MacKinnon continues:

'...Society is made of words, whose meanings the powerful control, or try to. At a certain point, when those who are hurt by them become real, some words are recognized as the acts that they are. Converging with this point from the action side, nothing that happens in society lacks ideas or says nothing, including rape and torture and sexual murder... It is not new to observe that while the doctrinal distinction between speech and action is on one level obvious, on another level it makes little sense. In social inequality, it makes almost none. Discrimination does not divide into acts on one side and speech on the other. Speech acts. Acts speak.' 43

None of this, of course, shows that MacKinnon's specific claims about what porn does are correct. What it shows is that MacKinnon does not need Austin. Her claims can be shown to be coherent and contentful without him. And no amount of staring at the pages of How to Do Things With Words will get us anywhere with the question of whether they are true - that is a question about concrete political reality.

Perhaps the most striking thing about this whole debate, in fact, is just how abstract it is, for the most part. Even Austin, as an 'ordinary language philosopher', was interested in the way in which words are actually used in real life - even though he was never able to fit that reality into the neat categories he had designed for it. One of the perceived advantages of the silencing argument, by contrast, was the promise of kind of 'flight from reality': a promise to airlift us out of difficult empirical questions of harm. That promise has in one sense been confirmed to be unkeepable: illocution and perlocution alike are contingent, causal phenomena, and we still obviously have to ask, of alleged instances of such phenomena, whether they happen or not. In another sense, recent incarnations of the silencing argument have kept the promise all too well, fixating not only on inflated Austinian distinctions but also on hypothetical rather than actual scenarios. We saw this most clearly in the treatment of a highly artificial 'rape myth' situation, discussed in Section II.ii). True, I argued that this was to be understood as a pedagogical model - and there need be nothing wrong with that. But a model has to be a model of something. In this case, the actual world, of which Langton's scenario might serve as a model, tends to slip out of view,

${ }_{43} \mathrm{ibid}, \mathrm{pp} .20-21$. Emphasis added. 
with the result that the model is confused with a naturalistic representation of the real thing - as which it is quite rightly rejected.

MacKinnon, for her part, treats this flight from reality with evident contempt:

'... one cannot help wondering why some schools of philosophy have become a place where what something actually does is not considered pertinent to the exploration of what it could or might do. Life is not a game of logic, an argument's plausibility is not unaffected by the social reality to which it refers, and power's denial of abuse is not a function of not having read a philosophical proof that such abuse is possible. ${ }^{44}$

\section{Conclusion: only porn?}

I've argued that, whilst there is something laudable in the attempt to render the silencing argument in terms acceptable to analytic philosophers, much is 'lost in translation' (as MacKinnon herself observes). ${ }^{45}$ Too often, it appears, what is lost is nothing less than reality itself - while a lot of unnecessary baggage is picked up along the way. I've argued that the debate over the silencing argument is continually derailed by a widespread fetish for J. L. Austin (and that MacKinnon understands this very well). Those involved in that debate do not, of course, regard themselves as effecting derailments, or as performing 'showy tricks'. Many see their project as one in the service of greater clarity and rigour, thereby potentially increasing the accessibility and persuasiveness of the silencing argument to an analytic audience. They should have given MacKinnon a bit more credit - and, perhaps, analytic audiences a bit less.

Of course, it's not only porn that affects the way in which women are seen - and hence what they can say, and how freely - in a way which renders them subordinate and unfree. Anyway, if we understand 'pornography' not as a class of material, but as an element which runs through the life and speech of patriarchal societies - their literature, their films, their music - then pornography, understood as the eroticization of hierarchy and oppression, really is everywhere. This is often raised as an objection to the argument that porn silences women: "if it applies to all that, then surely the argument proves too much!" Since it is assumed that this is a debate

\footnotetext{
44 ibid, p.iv.

45 MacKinnon (2012).
} 
about what the liberal state may and may not censor, ${ }^{46}$ and since nobody wants too much censorship, anything which threatens to reveal the full scope of the silencing argument's central insight is taken as a refutation.

This phrase - 'proves too much' - is deeply telling. You can't 'prove' that pornography should (or should not) be censored. That is a practical question, sensitive to a whole range of historical, social, political and strategic variables. It is also not the only question we might be interested in. What is too much to censor does not have to be too much to criticise or to fight. What is 'too much' to prove, or to say, always depends on what is true and what needs to be said. If the silencing argument really applies to 'all that', then we have to change all that.

In sum: if the arguments of this paper were to be reduced to a single motto, we could do a lot worse than "MacKinnon, not Austin!". The motto is best understood as designating not an end-point, however, but a point of departure.

\section{References:}

Antony, Louise. 2011. Against Langton's illocutionary treatment of pornography. Jurisprudence, 2 (2), 387-401.

Austin, J. L. 1962. How to Do Things with Words. Oxford University Press.

Berlin, Isaiah. 1970 [1958]. Two concepts of liberty. In his Four Essays on Liberty. Oxford University Press.

Dworkin, Andrea. 1979. Pornography: men possessing women. New York: Plume, Penguin Books.

Dworkin, Andrea and MacKinnon, Catharine. 1998. In Harm's Way: the pornography civil rights hearings. Cambridge MA: Harvard University Press.

\footnotetext{
${ }^{46}$ Cf. ibid, p.xvii: 'Why all these topics must be considered within the confines of liberalism is not broached even sideways, leaving liberalism assumed rather than interrogated.'
} 
Dworkin, Ronald. October 1993. Women and Pornography. The New York Review of Books.

Green, Leslie. 1998. Pornographizing, Subordinating, Silencing. In Post (ed.) Censorship and Silencing: practices of cultural regulation. Los Angeles CA: Getty Research Institute.

Hornsby, Jennifer. 2011. Subordination, silencing, and two ideas of illocution. Jurisprudence, 2 (2), 379-385.

Jacobson, Daniel. 1995. Freedom of speech acts? A response to Langton. Philosophy and Public Affairs, 64-79.

Langton, Rae. 1999. Pornography: a liberal's unfinished business. Canadian Journal of Law E Jurisprudence 109: 109-133.

Langton, Rae. 2009. Sexual Solipsism. Oxford University Press.

MacCallum, Gerald. 1967. Negative and Positive Freedom. Philosophical Review 76: 312-34.

MacKinnon, Catharine. 1987. Feminism Unmodified. Cambridge: Harvard University Press.

MacKinnon, Catharine. 1994. Only Words. London: HarperCollins.

MacKinnon, Catharine. 2012. Preface. In Maitra \& McGowan (eds.), Speech and Harm. Oxford University Press.

Maitra, Ishani. 2009. Silencing Speech. Canadian Journal of Philosophy 39 (2), 309-338.

Maitra, Ishani and McGowan, Mary Kate. 2012. Introduction. In Maitra \& McGowan (eds.), Speech and Harm. Oxford University Press.

Saul, Jennifer. 2006. Pornography, Speech Acts and Context. Proceedings of the Aristotelian Society 106 (1), 229-248. 
West, Caroline. 2003. The free speech argument against pornography. Canadian Journal of Philosophy 33 (3), 391-422.

West, Caroline. 2012. Words that silence? Freedom of expression and racist hate speech. In Maitra \& McGowan (eds.), Speech and Harm. Oxford University Press. 